\title{
This Sporting Mammon: A Normative Critique of the Commodification of Sport
}

\author{
Adrian Walsh and Richard Giulianotti \\ This is a copy of the Author's Original Text of an article whose final and definitive from, the \\ Version of Record, has been published in Journal of the Philosopby of Sport [copyright Taylor and \\ Francis], DOI: 10.1080/00948705.2001.9714600
}

To Cite: Walsh, A. and Robertson, R., (2001) This Sporting Mammon: A Normative Critique of the Commodification of Sport, Journal of the Philosophy of Sport, 28:1, 53-77.

Published Version Available At: http://www.tandfonline.com/doi/abs/10.1080/00948705.2001.9714600\#.U-PeufldV8E

\section{Introduction}

Since 1990 the commodification of popular sport has occurred at a remarkable rate. Although this process has been apparent since pastimes such as 'folk football' were formally codified as 'sports' in the 18th and 19th centuries, in recent times we have witnessed a qualitatively different kind of entry of market-centred processes into sport. In the only truly global sport - association football or 'soccer' - this 'hyper-commodification' has involved the greater professionalisation and global migration of players, the corporatisation of clubs, the proliferation of merchandising, rule-changes to draw in new customers, and a general redefinition of the competitive structures and ethos of the sport. There is understandable, intuitive unease amongst many members of the sporting community about these changes. How well founded are these concerns?

In this paper we identify a list of 'pathologies' - both moral and practical - which arise when sport is commodified. To develop and illustrate our discussion, we look at football, and in particular the Manchester United Football Club to enable more general claims about sport commodification to be advanced. Manchester United is routinely regarded as the world's most popular football club; in March 2000, the club had a market value of over $f_{1}$ billion, some eight times greater than its nearest English challenger. Here processes of commodification are particularly apparent. For instance, it is we suppose platitudinous to note that clubs like Manchester United are organised as transnational corporations and, beyond the rationale of the market, will have a tenuous relationship with their surrounding communities. Ownership of - or investment in - major sports clubs is now more inspired by 'venal' motives than by a communitarian quest for local public status or cultural 
custodianship. We believe that by developing our taxonomy in the context of contemporary sociological observations, we will help to explain the nature of community unease towards recent transformations in football. More broadly, the paper represents the opening salvoes in the formulation of a more general critique of the commodification of sport.

\section{The Commodification of Sport}

To begin, we need to define what is meant by the 'commodification of sport'. Evidently, the literature on commodification displays considerable variance in use of the term. A strict definition focuses on the system of production and exchange. A commodity is a good that possesses both use-value and exchange-value. A good is thus commodified when it changes from a good possessing only use-value qua the satisfaction of needs to a good that also possesses value as an exchangeable item. Other definitions of commodification look beyond this exchange process, and towards our attitudes regarding objects and practices. For instance, Elizabeth Anderson (1993) (and she is by no means alone) claims in Value in Ethics and Economics that a good is commodified either when it is bought and sold or when it is regarded as a thing with a monetary value (even if no actual buying and selling occurs). On this model, cost-benefit analysis, for instance, becomes a form of commodification. In a sport such as football, players will thus be valued as commodities even though they may have long-term contracts with a club which is disinclined to sell them.

Here, we adopt Anderson's wider definition; typically, the attitude that views objects and practices as potential commodities is an essential preliminary to the process of commodifying that object or practice through a set of market exchanges. Following from this, we also wish to understand commodification as an on-going process - rather than as a single event - of translating the social meaning of a practice or object into purely financial terms. In this sense, a cultural field (such as the sport of football) does not undergo a single, Gestalt translation from a non-commodified to a commodified state when an exchange value on its social practices is realized (for example, when a club decides to charge spectators gate-money). Rather, viewed as a process, the commodification of an object or process may be considered to pass through a number of non-evolutionary historical stages. $^{\text {ii }}$ In defining commodification, we believe that it is most useful to examine the process in the context of sport and to discuss the kind of phenomena that the term discloses. What follows below is a list of the salient phenomena that index the intensive commodification (or 'hyper-commodification') of sport. By hyper-commodification, we are referring to both the 
quantitative explosion in the value of sports like football and to the broader, intensive commodification of secondary, non-play aspects of the game. The former process is illustrated by the multiplication in the market value of top clubs ${ }^{\text {iii }}$, top players ${ }^{\text {iv }}$ and seats at football grounds ${ }^{\mathrm{v}}$; the latter process is instanced by the enormous increases in the value of club merchandising, television contracts with clubs, and the off-field earnings of players.

\subsection{Some Pathological Consequences of Commodification}

\section{(i) The corporatisation of clubs}

Elite sports clubs are now explicitly organized as corporate entities. Most have undergone some significant division of ownership and control along the 'joint-stock' model, while the wealthiest clubs have become capitalized as public limited companies that are listed on major stock exchanges. The corporatization of sports clubs, and their governing associations, entails the prioritizing of profitability within the sports enterprise over its historical, cultural, social or aesthetic dimensions. As transnational business corporations, these enterprises experience an increasingly haphazard and accidental relationship to their old, traditional supporter base in the localities surrounding the club stadium.

This represents a considerable transformation for those numerous sports clubs which had originated as community-based associations. In Latin America, sports clubs originated as private member associations and so were constitutionally organised as leisure democracies. Each club is owned by members ('socios') who pay a modest subscription every month or year and elect the office-holders on a regular basis. In the UK, prior to the First World War, most clubs had already become limited companies, and were owned by a small group of local shareholders who were keen to sustain their local profile and thus were accessible to the club's (often critical) supporters. With their 'hyper-commodification' since the mid-1990s, clubs have converted into limited companies. The new owners are either institutional investors or the existing share-holders whose wealth has been multiplied dramatically by capitalization. In both instances, the social and political gaps between those who run the clubs and those who support them must become qualitatively greater. Indeed, to all intents and purposes, they belong to increasingly distinct communities. Hyper-commodification also means that the club is valued according to its share price. However, this inevitably misrepresents the club's uniqueness in the eyes of the football community. 
One important feature of hyper-commodification then is corporatisation: that is, hyper-commodification involves the supplanting of more democratic structures or community-tied ownership by distinctively impersonal, corporate frameworks of power. Those clubs which do not adopt a corporate structure risk falling behind, effectively forfeiting their competitive potential. ${ }^{\mathrm{vi}}$ The overall effect at the elite level is a homogenisation of club corporate structures with power passing to a cartel of rich investors.

The elite sporting clubs come to act in the manner of corporations in the rest of the business world, hence we find in football practices and phenomena that parallel those found in other areas of capitalist industry. Two such phenomena are globalization and cartelization. Clubs like Manchester United are essentially trans-national entities: they evidence an international division of labour, not only in terms of signing many overseas players, but also their world-wide employment base for manufacturing and marketing club products. Top UK clubs have been actively pursuing new 'consumers' fans since the late 1960s, vii however as transnational enterprises with global media outlets, this process has been immensely successful since the early 1990s. Hence, Manchester United have actively pursued marketing opportunities in North America and the Far East, giving rise to distant global 'supporters' who may identify with the club through purchasing its merchandise, rather than in the old style of community fandom by attending matches or watching the players in training. For some analysts, this process is underpinned by the transformation of Manchester United from a grounded football club into what neo-Marxists would describe as a free-floating 'commodity signifier'.

The process of transition for clubs into fully fledged transnational corporations, that are decoupled from their surrounding community, is still incomplete. Top football clubs are still currently 'ethnocentric transnationals' in that they retain their traditional headquarters in their place of origin (such as Old Trafford in Manchester). However they do have the potential to become more 'geocentric' in both management and basic 'production': in other words, given their enormous supporter base throughout the UK and world-wide, Manchester United could easily follow the path of American and Australian sport 'franchises' by moving cities to play their 'home' football fixtures or relocating their business headquarters. Such a move would only further weaken the ties of club with community.

The cartelization of football is evolving through the broadening gulf in economic and political 
power between the superclubs - the so-called G14 that includes Manchester United, Real Madrid and Bayern Munich - and the rest in Europe. Cartelization involves the replacement of traditionally meritocratic competitive frameworks with new arrangements that guarantee the competitive status of Europe's richest clubs. In other words, one crucial norm that is integral to sport (reward for effective competitiveness on the field of play) is being superceded by matters that are external to the logic of sport (financial wealth). Due to pressure from the G-14, the European football authorities have reorganized their competitions, to allow more of the top clubs from the richest leagues to compete. In the longer-term, it is expected that the richest clubs will create their own international tournaments, excluding smaller clubs who, on occasion, might threaten to defeat the superclubs' teams and thereby eliminate the elite from lucrative competitions.

The globalization and cartelization of European football is enhanced by other, secondary processes. The richest clubs exploit their economies of scale to further their advantages over smaller clubs. Vertical integration enables the top clubs to contract with, or purchase shares in, smaller sides at home or abroad to ensure first options on emerging young talents. ${ }^{\text {ix }}$ Horizontal integration involves major transnational corporations with sports-related interests (such as media and communications businesses) investing in the richest clubs, enabling the latter to benefit from greater financial leverage and the marketing expertise of these new investors. ${ }^{x}$ The most compelling example of such horizontal integration comes from Italy where Silvio Berlusconi's Fininvest media empire acquired the ailing giant AC Milan in the early 1980's. Milan soon purchased a huge squad of the world's leading players to become Europe's premier club during the later 1980's and early 1990's. That pre-eminence encouraged Berlusconi to purchase the television rights to the top Italian league (Serie A) for his subscription channels. Media corporations benefit from their soccer interests, since they may sit on both sides of the table when television contracts are negotiated. Moreover, control of televised sport is often a crucial means of expanding into new media markets. For instance, Rupert Murdoch's unsuccessful bid for Manchester United during the 1998-99 season reflected his marketing philosophy that televised sport is a 'battering ram' for penetrating and controlling new television markets. Murdoch's bid was strongly opposed by many United fans on implicitly Kantian grounds: according to one group of independent supporters, "Every company he [Murdoch] owns or buys out is simply a means to an end", the latter being greater market share and profitability (Brown \& Walsh 1999: 58).

(ii) The professionalisation of players 
One of the most notable features of modern elite sport - and this is particularly evident in football is the professionalisation of players. Elite players are professionals in the sense that their income from on and off the field is derived through their public identity as sportsmen. In recent years, alongside the corporatization of clubs, we have witnessed an inter-related breakdown of the reciprocal loyalties which had obtained between the club and the player. This is not to romanticize or misrepresent the earlier nature of the player-club relationship. Before player contracts began to be challenged legally in the early 1960s, the players were often very exploited and offered few prospects beyond the game. ${ }^{x i}$ The 'maximum wage' policy at clubs led to illegal payments and may have contributed to corruption between players in fixing games; if players fell foul of management, a vindictive coach or director could effectively 'freeze' them out of the club and thus out of football. Notwithstanding these difficulties, we do seek to stress the communitarian relationships that bound players to the supporters and to clubs qua community representatives. Historians have noted how, prior to the mid-1960s, even the best players in the UK were viewed as local heroes, as community representatives with extra-ordinary talents, who slipped back into the surrounding fold outside of football, notably after retirement. ${ }^{\text {xii }}$ Players would typically spend most or all of their careers at one club, perhaps enjoying the communitarian benefits of a tax-free testimonial year to ease them into retirement. Supporters and management alike would be particularly sympathetic to those players who embodied the club's ethos and 'played for the jersey'.

Conversely, the greater professionalisation of sports athletes has resulted in a more active and flexible labour market. Elite athletes migrate regularly to new towns and cities, playing for clubs for financial reward rather than emotional or communitarian reasons. Correspondingly, clubs take on fewer responsibilities towards long-serving players while supporters have grown distrustful of the more 'mercenary' players who switch clubs regularly or enter into disputes with management and fellow players in pursuit of higher pay. Moreover, as contemporary celebrities, the top players have fewer personal ties with the club's surrounding community. In England, most players at the top 40 clubs earn over four times the average wage, hence they live in exclusive suburbs, interact rarely with supporters (save for situations that confirm their celebrity distance, such as in signing autographs or opening new businesses), but appear regularly in 'glamour' contexts (such as in television interviews or in the company of other celebrities). The immediate origins of the relatively sudden wealth and intense mobility of players are to be found in the 1995 Bosman ruling, in which the European Court ruled in favour of the Belgium player, Jean-Marc Bosman, in his civil case against the Belgium 
football authorities, and endorsed the rights of professionals to contract themselves to clubs in a free labour market. Players have understandably sought to employ, at last, the logic of the free market to their collective advantage.

In line with the EC's free market principles, the Bosman ruling also permitted clubs to field any number of players from other countries (previously, there had been strict quotas). General market-inspired problems emerge here concerning the development of young players. A dearth of local and national talent is nurtured by top clubs, who have turned instead to recruiting numerous overseas players. The problem is particularly acute in Spain and England, who face potentially serious problems in developing sufficiently talented players to compete at international level. More broadly, the new system may be seen to exaggerate the pre-existing, market-dominated industrial experience of players. In a Kantian sense, professional clubs tended to view players as means towards ends, placing relatively little emphasis on their personal development or on the tuition of players into those skills of the game that did not have practical value to the team. Such a practice is both immoral and dysfunctional: young players learn fewer skills, are less adaptable and competitive at the higher level, and have fewer personal resources to fall back on when they retire from the game. In nations such as France or Sweden, market norms are less explicit in player development, hence young players acquire a broader range of personal and playing skills, as ends in themselves, which also prove instrumentally efficient on and off the field of play.

\section{(iii) Venalization and the sporting ethos}

The corporatization of clubs, and the greater professionalization of players, can be understood in terms of a 'venalization' of the motivational principles. 'Venalization' arises when the pursuit of money or profit is seen as the sole aim of action. This philosophy was wonderfully encapsulated by the Australian media mogul Kerry Packer when, during negotiations with officials of the Australian Cricket Board, he remarked "Come on, we're all whores, what's your price?” In the world of soccer we find numerous instances of such venalization. For example, while supporters buy small share-holdings in clubs for emotional reasons, major institutions such as ENIC make major investments for purely financial reward.

In addition to such venalization, we find that the range of spheres in which money dominates has expanded. In elite sport, the allocation of resources is increasingly determined solely by money; thus 
one's 'sporting chances' are determined by relative access to money. In elite level soccer in Western Europe, there are no salary caps within the national leagues, no compensatory 'draft' system to ensure the weaker clubs pick up the best young players, and (following Bosman) no internal restrictions on player mobility. Consequently, as money can predetermine playing successes, the national football leagues experience a crisis in the 'uncertainty of outcome' that sporting events must contain if they are to continue to secure public interest in the game per se. In England, for example, Manchester United's financial power means that they have won the top tournament, the league championship, six times in eight years since 1992. Such domination threatens to undermine the competitive integrity of established football tournaments.

Another emergent feature of high-level sport is the proliferation of merchandising and advertising. This is reflected economically, as clubs derive less of their annual income from gate-money to survive and compete. Until the 1980s, football clubs drew most of their income from gate-money; in 1998, Manchester United's annual income comprised 34\% from gate-money, rising to 38\% in 1999 due to an exceptionally successful season in European football. Over that period, track-side advertising has been revamped, shirt sponsorship established, larger deals with shirt manufacturers have been signed, corporate hospitality and conference facilities created, executive boxes have been carved into main stands, and a smorgasbord of products has been manufactured under club names. ${ }^{\text {xiii }}$

In marketing terms, football clubs are branded commodities, hence supporting a team is understood as brand-identification with intensive periodicity. Sports fans are 'consumers' or 'customers' who, through heavy marketing, come to identify not only with clubs, but also with specific celebrity players and sports-good manufacturers. This merchandising exploits two deeply traditionalist principles of soccer culture: (i) that fans identify automatically with their team brand no matter where it sits (that is regardless of whether it sits on a shirt or a condom) and (ii) that fans do not switch teams (and hence will not switch brands).

One way of counteracting the alienating consequences of this process is to market the product as more than just a brand. Manchester United have been notably successful in pursuing this strategy. Whilst many clubs have reinvented themselves through a new 'corporate' image, Manchester United have engaged in a subtle commodification of their heritage. They have remained symbolically in touch with the mythology of their past. The club continues to play at Old Trafford; to trade with a 
'Red Devils' motif; to employ Alex Ferguson as manager and the legendary Bobby Charlton as a director. Merchandise advertisements draw strong symbolic connections between current United players and those of its illustrious past.

However, some sociologists have pointed towards the long-term redefinition of the principles of support for a club. They argue that, as the market philosophy takes precedence in sport, so supporters will come to switch teams (and brands) in order to identify with success or winners (Alt 1983). In that sense, the top clubs are now orientated towards consummating these principles of consumption, either through ensuring they continue to win trophies or, when defeated, by deflecting the attention of investors and consumers onto more positive developments (such as the signing of new players). Likewise, the 'repackaging' of sport for these new kinds of spectator or viewer means that the sport gives up its traditional norms and ethos, in favour of a degrading form of entertainment. ${ }^{\text {xiv }}$

Not only have the practices of sporting clubs changed, but unsurprisingly the self-understandings of those organising and promoting elite level soccer have been transformed. In a commodified realm, sport is understood either as entertainment or as a form of industry. We talk of sport as business: products with customers, workers, brands, market-share, stock market values and so on. Here we have the emergence of what the North American philosopher Margaret Jane Radin in her imaginative book Contested Commodities calls 'market rhetoric'. Market rhetoric involves conceiving of all human activities - even those that do not involve buying and selling - as fundamentally oriented towards the pursuit of money. Radin is thinking here of those such as the 'Law and Economics' movement who advocate that we apply cost-benefit analysis and shadow prices to all human activities whether or not they are commodified or are even capable of being commodified. In a similar vein, conceiving of soccer clubs as part of the entertainment industry is a way of incorporating them into such a commodified understanding of the nature of human interaction. The organisation of sport then comes to be understood within the discursive framework of 'market rhetoric': as either a form of diversionary entertainment or in explicitly industrial or commodity terms.

When we contrast market rhetoric with the ethos of sports, we find a definitive difference. For Morgan (1993: 224), the game's ethos represents "those attitudes, commitments, values, goods, and virtues that are necessary to sustain the ways of life embodied in sporting practices." Thus defined, 
the ethos of football - like all other sports - is not equivalent to the pursuit of money, but to the pursuit of victory, in competitive good faith, through social action that is both rule-following and aesthetically sanctioned by the participating community (the 'practice-community') of that sport (of which more later). Our definition of the ethos of sport is therefore somewhat broader and more sociological than that of D'Agostino which was, in turn, initially advanced to refute the rule-centred, formalist definition of games. ${ }^{\mathrm{xv}}$

\subsection{Traditional Fans and Commodification: a summary of claims}

The notion of a participating community is important here, in relation to our normative support for the interests of football's 'traditional fans'. Such a position requires us to advance a number of sociologically grounded claims. First, we consider traditional fan groups to be sporting communities that are worth preserving, because these furnish sport with many non-economic goods. They constitute sport's core communities, from whence all qualities of player spring; they have exercised the greatest quality and quantity of cultural labour in developing a sport such as football, in terms of bodily techniques, aesthetic codes and cultural practices. In return, sport provides these communities with some crucial non-economic resources. Sports such as football constitute one of the relatively few realms of collective articulation for these communities, many of which have tended to be relatively disadvantaged. The public cultures surrounding sport may be viewed as aggregated rituals through which the community can explore the contours of its common identity and express what its members are. Yet taken collectively, these communities provide the sports in turn with an enriching diversity of identities, as expressed for example through playing styles and supporter practices. Second, we submit that the current market-driven globalisation of sports is inimical to the interests of these traditional fans. The categorical redefinition of supporters to become consumers, and the pursuit of wealthier consumers by football's clubs and governing bodies, must impinge negatively upon the interests of these traditional followers. Following from this, and third, we may develop our point in relation to Dixon's (2000) taxonomy of sport spectators. In brief terms, Dixon (2000) distinguishes supporters on the basis of their apparent objective appreciation of the game; from this, he generates a series of claims about polarised fan identities. Hence, 'partisan' fans have a strong local attachment to specific sports clubs, but their subjective immersion may, in its extreme manifestation, preclude a principled appreciation of the game's fineries and ethics. These latter, more virtuous qualities are instead the preserve of those spectators whom Dixon dubs the 'purists', a category that also opposes parochialism and violations of the sport's rules and ethos. 
Dixon's useful binary classification does encounter some empirical problems when applied to football. In short, the very trendiness of football in the UK since the early 1990s has given rise to concerns among long-standing spectators and fans that those who seek to pass themselves off as 'purists' or 'connoisseurs' (with a cosmopolitan disdain for local attachments) are more accurately described as 'arrivistes'. Our traditional fans are certainly regarded as partisan, but it is precisely their deep and socialized immersion in the sport (as expressed in part through support for the club and its players) that tends to guarantee their 'purist' appreciation of the sport's laws, spirit and aesthetic codes. Conversely, the arriviste/purist fan comes to football through its mediation, such as on television, and employs that lack of personal engagement to create 'distinction' (typically class-rooted) from those who are allegedly too parochial to read the game's fineries. ${ }^{\text {xvi }}$ It is our concern, within the context of this paper, that these traditional fans, with richer 'stocks of knowledge' regarding the game's history and culture, are easily displaced by these arriviste supporters, purely on the basis of financial inequalities, such as the latter group's greater capacity to pay for expensive season tickets or pay-per-view televised fixtures. Fourth, from the above, we consider that there is no a priori normative division between players and fans. Given that the former spring from the latter's communities, if traditional fans are marginalised from the game, then the effective reproduction of playing resources is inevitably jeopardised: and this eventuality must be deemed pathological.

\section{Market Pathologies and the Commodification of Sport}

The illustrations of commodification given above serve to elaborate what we mean by the term and why we believe that soccer has been commodified. We now intend to identify some salient pathologies of the commodification of sport. The idea of a pathology is quite a simple one. It is not an objection in the fullest sense according to which it affords self-sufficient ground for prohibition or cessation of an activity. Rather, pathology locates an undesirable feature or consequence of market exchange which may or may not serve to warrant remedial public action.

\subsection{Venal Motives and the 'Olympian' Ideals of the Amateur}

Our position is that financial motives are now the dominant - and perhaps the sole - motive for the majority of collective and institutional actors in football. There is an obvious sense in which this state of affairs is somehow undesireable or even obnoxious, but how might we understand or make sense of this intuition? 
One initial philosophical response is to return to sport's 'core ethos', to the Olympian ideals of the amateur sportsman and the amateur club. Thus, the 'grubby' financial motives within contemporary sports are contrasted with the pure motives of the amateur, centring on goals such as the development of skills, competing at one's best and sportsmanship. Ex hypothesi financial motives do not enter into the calculations of such elite amateur sports persons. However, there are two ideological and historical problems with this position: (i) amateurism has an obvious class-bias, reflecting the ideology of the idle rich with independent incomes; ${ }^{\text {xvii }}$ (ii) the amateurist position is historically inaccurate as there has always been money - or at least commensurate reward - in sport since the time of the ancient Olympics. ${ }^{\text {xvii }}$

The modern Olympics are, of course, famously associated with the stated ethos of their founder, Baron Pierre De Coubertin, that the act of competing and struggling to excel is more worthy than victory itself. However, a fuller analysis of De Coubertin's views on sport highlights other, more divisive social values. ${ }^{\text {xix }}$ The ethos of amateurism ignores how other forms of social exclusion must inevitably penetrate an unprotected leisure sphere. Traditionally, amateurism served to promote the market's role in determining who can participate in sports: typically, the greater wealth and leisure time of dominant social groups prevented the involvement of subaltern groups. ${ }^{\mathrm{xx}}$ We are therefore not advancing a simplified normative dichotomy of impure financial motives and pure non-financial ones; rather, we need to make a more qualitative distinction between decisions in which financial considerations are taken into account and decisions in which financial decisions are totally determining. The person (or organisation) who is only motivated by financial considerations: (1) exhibits morally pernicious behaviour and more importantly; (2) subjugates more important values (such as the competitive ethos of sport) to the logic of the market. Whilst financial considerations are often necessary they should not be dominant in the all-things-considered reasoning of those entrusted with the development of sport. Commodification of sport is pathological then when it leads to such venalisation: that is, to a dominance of financial motives.

\subsection{Community-Identity and the Dedicated Fan}

Modern sports institutions, in both professional and amateur formats, have traditionally emerged through strong ties with their surrounding communities. Many sports clubs, including football ones, were formed specifically to serve the recreational needs of local people or even to operate as charitable institutions for the needy within the community. ${ }^{x i}$ While the best clubs became limited 
liability companies and recruited professional players, strong community associations remained between the club qua emblem of the locality and the local people qua supporters of the club and habitués of its premises (Giulianotti 1999; Holt 1989: 159-163). These club-community ties have been particularly apparent in the relatively working-class neighbourhoods of the UK's major industrial cities. The club was a strong source of local and civic pride, an important component of what Raymond Williams has termed the 'structure of feeling' within working class communities. Thus, supporting the local team and 'getting behind it' during matches was certainly instrumental (in encouraging the players to win), but also represented a validation of the local community before others. A key component of this identification is a refusal to give up on the club entirely, particularly when the team is playing poorly. In that sense, the most committed groups of traditional fans view their support as a kind of unbreakable social contract. Switching club allegiances is unthinkable. The communitarianism of local supporters is further reflected through the genesis of specific fan sub-cultures, such as informal supporter groups, independent fan associations, fanzine producers and so on. ${ }^{\text {xii }}$

However, with the hyper-commodification of football - and its principal manifestations, as we have outlined them - such community-centred ties are endangered. Clearly, this commodification inevitably involves the attraction of new spectators into football. However, the effects of these changes upon the interests of the traditional or dedicated fan must be a source of concern.

There are two obvious ways to tease out the pathological nature of these changes: the first concerns the values expressed in sport and the second concerns distributive access. In terms of expressive concern, the philosophical intuition here is that actions are valuable not only in terms of consequence, but also in terms of the ideals and attitudes they express. For instance, whether I take offence when your elbow jabs into my stomach depends upon what your intention was and what you intended to express by your action. If it was an accident then my reaction will be different than if you intended to harm. The pure consequence in terms of harm may be the same. What makes the difference is what the action expresses, a thought which Elizabeth Anderson develops in great detail in Value in Ethics and Economics. Anderson is particularly concerned with the disjunction between the expressive meanings of markets and those of other important human activities. She suggests that actions often have expressive meanings which markets and market norms are not capable of expressing. 
Not only philosophers, but numerous social theorists have advanced the argument that the meaning of any form of human communication cannot be routinely reduced into quantifiable terms, and particularly not into pure commodity terms. For example, those who incorporate a hermeneutic approach to the human sciences, in opposition to a positivist perspective, argue that the meaning of any object or action is fraught with historical and cultural complexities. ${ }^{x i i i}$ Hence, if we explain an individual action in terms of market norms and meanings, we are making two highly contestable statements: first, we assume that the action's author is deploying a market logic in line with his or her cultural traditions; second, we are arguing that within the 'traditions' of the humanities, the use of such an economic model is a legitimate explanatory tool for understanding social behaviour. We also consider that context-centred caution here, regarding the reduction of expressive actions to economic principles, is in line with our subsequent points regarding community identity and football support.

We can apply these general ideas to the plight of the traditional soccer fan. We might say that there are particular expressive meanings and qualitative ideals that are constitutive of the practices and traditions of the traditional soccer fan, and that these have been entirely disregarded in the recent corporatist development of the game. The logic of hyper-commodification thus threatens to undermine or destroy those meanings. Consequently, we may conclude that commodification is pathological when it leads to the violation of the expressive meanings of the central culture of the game.

Of course, there are dangers of a communitarian inspired moral relativism here since there is no reason to believe that we should support the values of a community simply because they originate in a community. Indeed, some community meanings may well be morally repugnant. Moreover, there are also difficulties of interpretation since such meanings are rarely univocal. In a football context, for example, we may imagine a scenario in which the community club is a focus for strong, local racist traditions, but which are not expressed univocally. Such a case alerts us to the possible need to over-ride some communitarian meanings to ensure the establishment of basic, universalist principles regarding social tolerance and justice. However, we should be wary of attempts, by those favouring the eradication of communitarian traditions, to represent localist sentiments in this intolerant manner. This has certainly occurred alongside the commodification of football, in terms of seeking to harmonise the perceived xenophobia, sexism and violent tribalism of community supporters through their exposure to new kinds of football consumer. 
Many important community ideals and norms have been violated by hyper-commodification. However, what deliberative force we should accord such considerations is an open question, since it is hard to know how, for instance, one could legislate for meanings, even if one can identify an unequivocal account. So whilst it may well be pathological, it does not seem to be a live candidate as a reason in our all-things-considered determinations.

A second - and we think more perspicacious - way of teasing out how commodification might be pathological with respect to the interests of the traditional fans is in terms of those fans' distributive access. In the distributive realm, commodification is pathological when:

(i) it excludes persons from goods to which they previously had access

(ii) it excludes persons from access to goods which are central to personal and social life

Whilst there may be some doubt as to whether (ii) applies here - more of which later - (i) certainly is apposite. Traditional soccer fans have been excluded through many of the features of hyper-commodification - such as the refurbishment of stadiums, the construction of corporate boxes in areas once occupied by the traditional fans, the increase of gate-prices over the rate of inflation - from resources to which they once had access. So one serious cause for concern is in the distributive realm. Any policies with respect to commodification of sport would need to take such concerns into account. We might say then that the commodification of sport is pathological when it leads to the exclusion of traditional soccer fans from resources and activities to which they once had access.

Distributive pathologies are most evident in immediate, empirical instances through the maltreatment or social exclusion of specific, traditional supporters. For example, at the 1995/96 European Champions League tournament, Manchester United followed European convention by introducing large advertising boards along the perimeter of the pitch. The boards would have blocked the sight-lines of fans seated in bottom rows of the stands, hence no tickets were sold for these sections. In effect, the club had reduced access to these highly prestigious matches to accommodate advertisements. At the 1998 World Cup in France, major corporate sponsors paid $\$ 20$ million apiece to secure privileged advertising and seating spaces at the expense of tickets for dedicated supporters. In Newcastle in 1999, dedicated supporters who had purchased long-term seats within the ground were permanently relocated to inferior seating, so that the club could charge wealthier corporate groups a higher price for prime positions. More broadly, we may also consider 
the hyper-commodification of the televising of football. Armchair supporters are now required to pay monthly subscriptions to view important matches that they might previously have watched on free-to-air television. All of these examples are, we contend, distributively pathological.

To illuminate further the nature of this distributive pathology, we need also to place access to sporting events within a historical context. Sport and leisure activities have acquired greater cultural importance in Western, post-industrial societies, in terms of their health benefits and (at elite level) their centrality to everyday public experience. More broadly, we may note that access to cultural resources has become, for social scientists, an increasingly important tool for measuring levels of relative inequality, poverty and deprivation within Western societies. Christopher Berry (1994), for example, has noted that some theorists consider that access to television is one important index of citizenship within the contemporary world. Hence, elite sporting events may be considered in equivalent terms. They are viewed increasingly as important public goods; access to these goods must be considered in terms of cultural citizenship and civil rights at the cultural level. It thus follows that the commodification of sport is pathological when it excludes persons from access to these goods, either at the actual level (in match attendance) or the virtual level (on television or other media). How plausible this line of argumentation is will depend upon the kind of sociological evidence which can be mustered to demonstrate that access to sporting goods is central to cultural citizenship. Whilst not wishing to commit ourselves here, we believe that this might well be a fertile line of inquiry.

\section{$\underline{3.3 \text { Market imperialism and the domination of money }}$}

In Spheres of Justice, the North American philosopher Michael Walzer (1983) notes that in contemporary societies different goods are distributed by different principles and mechanisms. Walzer emphasises the need to distinguish distributive spheres and to prevent criteria from any one sphere from dominating in all spheres. In particular, Walzer emphasises the importance of thwarting money from dominating all spheres; if money does so, it must undermine our civic community which Walzer (1983: 29) describes as "the most important good." Walzer believes in what he calls 'complex equality' whereby inequality and domination in particular spheres is acceptable, but it is not legitimate for persons to dominate across a range of spheres. Commodification undermines complex equality because it increases the range of spheres in which those with money can dominate. As we have seen regarding horizontal and vertical integration, sport is dominated by those who dominate 
in other spheres. In soccer, for example, both the relative successes of clubs, and the political and competitive structures of the game, are dominated by those with wealth. Commodification then is pathological when it allows those with money an undue influence in the development and control of sport.

Some counter-arguments have been forwarded which centre on the market's utility in democratizing sport and in protecting the ethos of sports. We may term these viewpoints the 'argument for market democratization'. For example, Tamburrini (2000a: 37; 2000b: 205) advances the view that commercialisation of sport has enabled top athletes from ethnic minorities to become positive role models, while providing many non-elite sports people with good standards of living. (Both of these social benefits could, of course, be achieved without recourse to the commodification of sport). Elsewhere, it is argued that, as consumers, football spectators are more likely to complain about the violent conduct of players, or any abusive gestures that are made by players to spectators - both of which may be counterpoised with the sporting ethos of football. ${ }^{\text {xiv }}$ Additionally, it is argued by some that football's 'traditional fans' have tended to constitute a relatively chauvinistic, intolerant community of white, male, working-class supporters. In repackaging football for market consumption, it is argued, new communities of supporters have been attracted to the game: women, families, ethnic minorities, more middle-class supporters, and more purist fans who are more admiring of skilful play. ${ }^{\mathrm{xx}}$

When combined, these arguments may challenge the communitarianism argument on the grounds of a corrosive, self-interested moral relativism: the football ground is dominated by highly partisan teams and supporters who fight to retain community pride and values, paying little heed to the more universal ethics of competitive sport. However, we reject these arguments on empirical and analytical grounds. First, the xenophobic aspects of football's traditional custodians are being exaggerated here. Second, there is little evidence that new, disadvantaged communities (such as ethnic minorities or working-class women) have started to attend matches in far greater numbers. The most appreciable difference is in class terms, with wealthier fans now much more apparent at matches. Third, we follow Walzer's position, in that we are clearly not opposed to the challenging of essentially intolerant and unjust communities according to universal principles. However, in more usual circumstances, we do object to situations where communities are disenfranchised, or where they are not given the resources or the opportunities to adjust to the new conditions that are being established. Generally, we are concerned that the 'argument from market democratisation' represents a basis for disenfranchising traditional fans, after establishing false premises concerning 
the need to 'civilise' the game's 'practice-community' of fans.

\subsection{Corrosion of the Integrity of the Game}

Commodification not only involves a change in the mechanism of distribution but often brings with it a transformation in the goods and activities commodified in themselves. This is as true in sport as it is anywhere else. Commodification is pathological when it changes the nature of goods so that their valuable features are eliminated or transformed in ways that are undesirable. The kinds of changes most relevant to the sporting case are those that have to do with the integrity of the game. Here we are particularly interested in cases where considerations that are outside of the game's 'internal logic' come to dominate.

An obvious example of this is when gambling interests pay players to throw matches. Here the integrity of the game is damaged because part of the value of any game, both for the spectators and the players, is that it is a genuine contest between contestants trying to win. This is, of course, a form of commodification, but it is not the kind with which we are most concerned. There are more insidious and legal ways in which the integrity of the game can be corrupted through commodification. Rule changes, which increase the spectacle for television audiences, but which diminish the subtlety or sophistication of skills required on the part of the players, would count as such a form of corruption. Commodification of sport then is pathological when it corrupts the integrity, or internal logic, of the game in question.

\section{Some Pragmatic Objections}

In the previous section we considered at length moral grounds for concern with the commodification of sport. However, there are pragmatic grounds-which we might file under 'market failure' - for concern, the first of which involves crises of legitimation.

\subsection{Legitimation Crisis}

The term 'legitimation crisis' originated with Habermas (1976). ${ }^{\text {xxvi }}$ Here, we employ the term in a rather broader sense than does Habermas, to denote merely that the commodification of sport undermines the sport in question as an object of value and focus for loyalty.

Consider two ways in which such legitimation might occur in sport (or more specifically soccer) 
(i) If it becomes apparent that the sport is oriented solely towards the maximisation of money then there might well be a backlash against this venalisation.

(ii) If it becomes apparent that sporting success is a function of money.

First, if it becomes blatantly apparent that pursuit of money is the central concern, then the sport may well lose its value as a commodity. Consider the following example that discloses the venal motive in contemporary sports. At a match against Southampton in September 1996, Manchester United introduced its official third strip for players for the 1996-97 football season. The move was widely criticised beforehand by media and supporters as a marketing ploy, aimed solely at selling a redundant third kind of strip to fans. The club lost the match heavily; afterwards several players and the club coach criticised the new grey strip, arguing that it undermined the visibility of team-mates during play. The club then withdrew the official status of the strip, leading to an outcry among thousands of fans who had bought it in good faith.

As we have noted, commodifiers require to obfuscate the process by which a good is redefined in purely market terms. From the marketing viewpoint, it is disastrous if consumers come to understand the commodity as only a commodity. However, so long as the more powerful figures within football come to view its goods in this way, there is always a danger that such a perspective will become equally transparent to the public, thereby undermining the game's attraction.

As to the second proposition, we have already noted - in 'money as the universal pander' -that the hyper-commodification of sport leads to a decline in its competitive content, most obviously signified by the domination of the richest clubs. This, as we have noted, involves a loss in sport's 'uncertainty of outcome', may engender cynicism regarding sport's claim to meritocratic values, and thus provides pragmatic grounds for concern about the effects of commodification. Commodification, then, is pathological if it leads to a loss of supporter interest, and to cynicism about the authenticity of the sport as a sport.

\subsection{Contradictions of Reproduction}

Here, we consider that the short-term logic of commodification may undermine the successful reproduction of the sport's practice-community of fans and players. If football is viewed as a cultural field for extracting surplus value, then the removal of money from the game may harm its long-term development. One concern here is that too little is being invested in football's grass-roots, 
particularly in sustaining a strong playing culture at non-professional level, which serves to educate future professional players and to link them socially to their surrounding communities.

Long-term problems of cultural reproduction also arise with supporters, as short-term profit motives favour new fans at the expense of traditional ones. In this context, it is useful to differentiate traditional and new fans in terms of the local/cosmopolitan dichotomy. Cosmopolitan supporters may be viewed as football flâneurs, drawn to the game by its marketing and mediation, preferring to peruse the most fashionable aspects of football, with little sense of 'place' or long-term, grounded identification with a specific club. Local, traditional fans, as we have seen, have a different quality of relationship to football. While the former may profess a detached, critical relationship to football, there is, as Walzer (quoted in Carleheden and Gabriels 1997: 120) points out, "a sense in which the cosmopolitan is parasitic on people who are not cosmopolitans." If the locals did not remain at home to reproduce the communitarian football cultures, there would be little for the cosmopolitan to experience, and little of football value to engage with. Thus considered, the rise of new fans is pathological in threatening to 'kill the source' by jeopardising the reproduction of established football communities. So commodification is pathological when it threatens the long-term viability of the game through short-term exploitation of resources.

\section{Possible Responses}

The pathologies that we outlined in 3 and 4 generate concern with the increasing commodification of soccer and, more generally, all elite level sport. We believe that the considerations outlined above will be pertinent mutatis mutandis to all other sports. Our intention now is not to provide a policy-centred framework for remedying these pathologies. Rather, we propose to remain at this stage within a moral philosophical perspective by forwarding some principles that may underpin practical responses to these pathologies.

\section{Consulting the 'Practice-Community'}

The idea of a 'practice-community' is forwarded by Morgan (1993: 234-7) to explain the nature of sporting communities. Morgan argues that community generally is an 'internal good' of sport, which is thus available only to those who practice within the sporting fraternity. Morgan is correct to argue that attachment to a sport's practice-community is not primarily voluntary, but one that is rooted in socialization, particularly at an early age. (This accords with our earlier point regarding traditional fan 
ties to clubs, but the professionalization of players obviously weakens their links to specific clubs). The aims of community members are shared and commonly espoused; quoting Sandel, Morgan notes that "community describes not just what they have as fellow [practitioners] but also what they are." To ensure that its members do not exit from the community, Morgan (1993: 250n) recommends that we 'spruce up' social practices, cultivating those aspects that initially retained our interests. xxvii Although Morgan tends to talk specifically of athletes as members of the practice-community, we would argue that in football at least we need to include non-players, particularly supporters, employees and officials within sports. ${ }^{\text {xxviii }}$

In a deliberative capacity, Morgan recommends that the practice-community should function as a critical tribunal, weighing any rival values or beliefs on the basis of rational merit, and seeking to establish rational consensus without recourse to self-interest or horse-trading. Morgan's practice-community thus has striking parallels with Habermas's utopian ideal speech situation, in which the debaters "come into the athletic forum armed only with their arguments, leaving behind all titles, goods, and vantage points that derive from their standing in other spheres" (Morgan 1993: 242). Crucially, however, Morgan sustains that the 'precious fineries of sporting practices' cannot be understood overnight, but require "cultivation, discipline, study, and diligence." Accordingly, those who are 'rational authorities on the game' exist in a master-apprentice relationship with relative novices, primarily at the opening stages of the latter's sporting practice.

The idea of a practice-community is certainly in keeping with our argument. Morgan confirms our concerns regarding the reduction of sport to commodity form, particularly in terms of the degradation of sport and community harm. Although they are far off from realizing Morgan's model, there are signs of an attempt by those generally excluded from the practice-community to establish a basis for more regular contributions to the football debate. At club level, the practice-community must be seen to include club directors and officials, who tend to establish club policy through share-holders' meetings, but also players and coaches, and supporters. Within each category, master-apprentice relationships clearly exist, although commodification does threaten to destabilize that kind of relationship within supporter groups by favouring wealthier fans over poorer, more traditional fans on the grounds of money. The growing communicative division between the ordinary supporters and the paid employees at football clubs (particularly the directors) has given rise to independent supporters' associations and other forms of fan sub-culture which seek to espouse their views. ${ }^{\text {xix }}$ At Manchester United, a network of fan groups contributed very strongly to 
the blocking of a take-over bid by the media magnate Rupert Murdoch on the grounds of his company's venal motives. At national level, the Football Task Force was created by the government to consult all those who were part of football's practice-community on the game's development. Significantly, the Task Force was unable to reach agreement on its findings, and published two final reports: one that was sympathetic to business interests in the game, and another that was more critical of commodification. Criticisms have been advanced regarding the degree of representation that these various independent fan organisations may claim. Nevertheless, we would argue that understanding the football public in terms of a practice-community, with the definitive features as noted above, provides a valuable and legitimate framework upon which the future development of football may be debated.

We consider that the practice-community is confronted with two broad issues when seeking to protect football from the pathologies associated with hyper-commodification. First, it needs to distinguish between three kinds of good within football: those that cannot logically be commodified; those goods that should on moral grounds be prevented from being commodified; those goods that should and can be prevented from commodification in practical terms. Second, within this final category, the practice-community needs to differentiate between two possible approaches: 'blocked exchange' and 'incomplete commodification'. We consider both of these issues in turn.

\subsection{Football Goods: logical, moral, practical considerations}

First, as Andre notes, some goods such as love and friendship defy commodification in logical terms. ${ }^{\mathrm{xxx}}$ Here, we may identify two aspects of football that cannot be commodified: love and respect. Love is constituted within an intra-community relationship, that is to say between the club and its fans. Respect emerges through an inter-community relationship, between the various groups associated with one club, and those other groups who are part of football's broad practice-community. Hence, love and respect as abstract values within the game cannot be commodified; one can only ever buy ersatz tokens of these valuable things.

In football, supporters talk expressively of their 'love' for the game and for their club; familial metaphors are sometimes employed, to describe the club as a 'mother' to its supporters. Hence, this affective, familial relationship with the club cannot be reduced to market principles, in which supporters' consumption of football commodities (such as the buying and wearing of club 
merchandise) captures the nature of the club-supporter nexus. Similarly, respect is earned by those clubs that play or organise their football in a manner that is in line with the sport's ethos. Clubs which seek to 'buy success', through heavy involvement in the player transfer market, may not be accorded the respect that their records of success would otherwise appear to warrant. Moreover, 'glory hunting' supporters, who visibly attach themselves to the most successful clubs, tend not be accorded respect by other fans and football people on the basis of their poor appreciation and understanding of the game. Hence, love and respect, as abstract values within the game, cannot be commodified.

There are many practical features of football that do appear to be drawn, rather pathologically, into market exchanges through the hyper-commodification of the game. We shall restrict our discussion to five aspects of football that, on moral grounds, may be considered worthy of at least some protection from commodification: player transfers, club ownership and control, televised football, access to football fixtures, and football-related clothing and paraphernalia. Protection from commodification may take two forms.

Blocked exchange refers to that set of regulations or principles that prevent a good from being exchanged on the market. Blocked exchange may operate in a wide range of social relationships: indeed, Andre (1992) provides seventeen types of blocked exchange in her taxonomical approach. Anderson (1993) argues that, to block exchange, the State should consider how 'noneconomic goods' may be protected from corruption by market norms. As our examples below suggest, while the national State may act, football's governing authorities may considered as the game's internal 'State' and so is similarly equipped to block exchanges. Alternatively, 'incomplete commodification' is a term coined by Radin (1996) to describe a less interventionist, more piecemeal strategy in challenging the commodification of public goods. The philosophy here is essentially pragmatic in working within the parameters of the market to enable broader public access to commodified goods, or to redistribute commodified goods, rather than to block the actual process of commodification. In some cases, such as football clothing, a complete prohibition on commodification is essentially illogical; in other cases, such as club ownership and control, the prevention of market exchanges is desirable but impractical; in other cases still, blocked exchange is relatively viable. Inevitably, there are some areas in which blocked exchange and incomplete commodification come together.

It would be highly impractical, to the point of absurdity, to advance the argument that all of world 
football should be protected from market penetration through a blanket application of blocked exchange. The game is an advanced state of commodification, the nature of which defies dismantling through a single, silver bullet policy. Philosophically and practically, football's global organisation is underwritten by transnational, free market legal statutes and trade agreements. The world governing body, FIFA, is organised as a major transnational corporation. Even if some governments imposed a policy of blocked exchange externally and unilaterally on football, this would certainly serve to advance the competitive inequalities between nations. Technological innovations, such as global internet broadcasting, would also strongly undermine any national impositions of blocked exchange in terms of media sport policy.

Strategies of blocked exchange may be more successfully introduced when they seek to protect basic forms of human rights. For example, Article 1 in UNESCO's international charter declares that, "The right to physical education and sport is fundamental for everybody." Most obviously, we take this to mean that, in terms of personal development and social membership, access to basic sports facilities (such as a local sports centre) is a human right and thus, by extension, to be the subject of blocked exchange. In terms of cultural citizenship, people also have a right to access elite level sport, particularly for 'prestige' fixtures within football at domestic and international level. Hence, we advocate policies of blocked exchange, such as a much tougher version of the anti-siphoning legislation in Australia, for the televising of prestige fixtures. ${ }^{\text {xxi }}$ Finally, blocked exchange should also be introduced to protect industrial human rights. Boycotts and bans on trade should be introduced for football-related products that are manufactured under deeply oppressive political regimes (such as in South Africa during apartheid) or industrial archipelagos (such as with some factories in the Far East or with child labourers in Pakistan).

Incomplete commodification may be recommended for social practices in which some kind of market relationship is universal or logical. Two obvious examples here concern supporter admission to grounds, ${ }^{\text {xxii }}$ and supporter merchandise. ${ }^{\text {xxiii }}$ In both instances, we advocate reductions in the actual price of the goods on offer (match entry, club paraphernalia). In the former instance, this should be targeted to include socially marginalised groups within the community. Reducing merchandise prices would help to enhance cultural inclusion in the context of a global society that is increasingly dominated by consumer-centred senses of identity and belonging. Other, derivative forms of incomplete commodification may represent the most practical, initial first steps against the hyper-commodification of football. We have in mind here some kind of ceiling on the charges made 
for televised football in general; the redistribution of wealth through a levy on top clubs to assist smaller clubs and football development projects; tighter regulations should be imposed on the activities of football agents in the developing world, especially in their contractual exploitation of talented young players.

Outwith the area of human rights, blocked exchange may be employed in a secondary way, and thus act in concert with the policy of incomplete commodification. We may identify three important areas in which this occurs: protecting supporter access to prestige matches, establishing the corporate structure of football clubs, and player development and recruitment. First, blocked exchange should be employed to prevent corporate enterprises or wealthy, 'neutral' spectators from acquiring tickets to prestige fixtures, to the exclusion of the more committed, long-term supporters. 'Incomplete commodification' arises here when the protected tickets are sold on to local, dedicated supporters. Second, in terms of club policy, we would favour a semi-corporatist model that parallels the French system whereby local authorities play a significant role in the corporate structure of the club. This constitutes a system of incomplete commodification, whereby a major (though not ruling) share in the club is held by local business, and the club itself continues to charge for use of its facilities. Nevertheless, in this way, the club is protected from pathologies relating to its 'value' being calculated purely in market terms, and its possible liquidation through ineffective or malicious business management. Third, in terms of player sales, we do not advocate a return to the iniquitous, career-long 'contracts' that blocked the transfer of players between clubs. However, to protect player development, there requires to be some form of training system for younger players that is controlled independently and free from market domination; this would require a ban on young player transfers, perhaps until the age of 23. To enable young players to play their way into the game, some kind of quota system needs to be reintroduced regarding the fielding of 'non-nationals' - a measure that is de facto a 'blocked exchange' one. Ideally, the professional league (rather than the individual clubs) would take the main role in contracting and distributing players between the clubs, thereby blocking the exchange of players between clubs (a practice that is pathological in grossly undermining effective competition between teams).

\section{Conclusion}

Although sport is often perceived as a sphere entirely independent of, and distinct from, the economy-indeed for many sporting enthusiasts the opportunity to escape from the economic 
considerations associated with work is the central attraction of sport-on our analysis sport has been commodified and as such displays a great many of the salient features of other forms of economic activity. Here, we have undertaken a normative analysis of the relationship between sport and social processes of commodification, identifying circumstances under which the commodification of sport is pathological (and we make no pretence that the list is exhaustive). Our identification of pathologies of the market should not be confused with the related, but more radical, claim that the commodification of sport per se is pathological; rather it is simply the claim that when particular undesirable outcomes arise, which are directly attributable to the commodification of sport, then such commodification is pathological. So, for instance, commodification is pathological when it violates the internal logic of a particular sport. This is not to say that marketisation is in itself or in toto pathological. The hyper-commodification of football has, however, given rise to particular kinds of market entry that we consider to be pathological within sport. Equally, we do not wish to contend that 'blocked exchange' or 'incomplete commodification' are in themselves fair or just practices: as we have seen, in pre-Bosman days, 'blocked exchange' served to tie players to clubs, sometimes against their wishes, while 'incomplete commodification' served to curtail their income relative to that of their employers. One function of Bosman has been to concentrate the minds of football's authorities regarding the impact of the free market on the game. In this sense, a potential space opens for wider public consideration of the broader iniquities of these free market principles within football.

The primary purpose in identifying our list of pathologies is two-fold: (i) to provide the basis of a critique of the commodification of sport and; (ii) to give shape to the justified intuitive concerns of many in the sporting public about the increasing marketisation of sport. Any form of critique would be oriented towards the amelioration or prohibition of pathological forms of commodification. Hence, the identification of such pathologies should play a role in determining which remedial measures might be adopted, regarding blocked exchange, amelioration or non-intervention. These issues must be resolved by the practice-community of the sport, not by market caprice.

\section{Acknowledgements}

We wish to thank the delegates at the conference 'Between a Rock and a Hard Place: Philosophy, Ethics and Competitive Sport', St. Martin's College, Lancaster, England, 10-12 April 2000 for their constructive comments on an earlier version of this paper. Thanks are due to Adam Brown for providing some details regarding Manchester United, and to the journal editor and three referees for constructive comments on the earlier version. 


\section{References}

Alt, J. (1983) 'Sport and Cultural Reification: from ritual to mass consumption', Theory Culture and Society, 1(3): 93-107.

Anderson, E. (1993) V alue in Ethics and Economics, Cambridge, Mass.: Harvard University Press.

Andre, J. (1992) 'Blocked Exchange: a taxonomy', Ethics, 103: 29-47.

Berry, C.J. (1994) The Idea of Luxury: a conceptual and historical investigation, Edinburgh: Edinburgh University Press.

Bourdieu, P. (1984) Distinction: a social critique of the judgement of taste, London: Routledge.

Brown, A. \& A. Walsh (1999) Not for Sale: Manchester United, Murdoch and the defeat of Bsky B, Edinburgh: Mainstream.

Carleheden, M. \& R. Gabriels (1997) 'An Interview with Michael Walzer', Theory Culture \& Society, 14(1): 113-130.

Coddington, A. (1997) One of the Lads, London: Harper Collins.

D’Agostino, F. (1981) 'The Ethos of Games', Journal of the Philosophy of Sport, 8: 7-18.

Dixon, N. (2000) 'The Ethics of Supporting Sports Teams', paper to the conference Between a Rock and a Hard Place: Philosophy, Ethics and Competitive Sport, St. Martin's College, Lancaster, England, 10-12 April.

Elias, N. \& E. Dunning (1986) Quest for Excitement: sport and leisure in the civilizing process, Oxford: Blackwell.

Giulianotti, R. (1999) Football: a sociology of the global game, Cambridge: Polity.

Goldman, R. \& S. Papson (1998) Nike Culture: the sign of the swoosh, London: Sage.

Greenfield, S. \& G. Osborn (1999) 'From Feudal Serf to Big Spender: the influence of legal

intervention on the social status of English professional footballers', Culture, Sport, Society, 1(1): 1-23.

Gruneau, R. (1983) Class, Sports, and Social Development, Champaign, Ill.: Human Kinetics.

Guttmann, A. (1978) From Ritual to Record, New York: Columbia University Press.

Habermas, J. (1976) Legitimation Crisis, Cambridge: Polity.

Hargreaves, J. (1986) Sport Power and Ideology, Cambridge: Polity.

Hoberman, J. (1984) Sport and Political Ideology, Austin: Texas University Press.

Hoch, P. (1973) Rip Off the Big Game, New York: Anchor Books.

Holt, R. (1989) Sport and the British, Oxford: Oxford University Press.

Horak, R. \& W. Maderthaner (1996) 'A Culture of Urban Cosmopolitanism: Uridil and Sindelar as Viennese coffee-house heroes’, International Journal of the History of Sport, 13(1): 139-155.

Kidd, B. (1984) 'The Myth of the Ancient Games' in A. Tomlinson \& G. Whannel (eds) Five Ring Circus: money, power and politics at the Olympic Games, London: Pluto.

Loland, S. (2000) 'Justice and Game Advantage in Sporting Games', in T. Tannsjo \& C. Tamburrini 
(eds) Values in Sport, London: E \& FN Spon.

Mason, A. (1980) Association Football and English Society 1863-1915, Brighton: Harvester.

Mason, A. (1996) “'Our Stephen and Our Harold”: Edwardian footballers as local heroes', International Journal of the History of Sport, 13(1): 71-85.

Mignon, P. (2000) 'French Football After the 1998 World Cup: the State and the modernity of football', in G.P.T. Finn \& R. Giulianotti (eds) Football Culture: local contests, global visions, London: Frank Cass.

Morgan, W.J. (1993) Leftist Theories of Sport: a critique and reconstruction, Urbana: University of Illinois Press.

Radin, M.J. (1996) Contested Commodities, Cambridge, Mass.: Harvard University Press.

Tamburrini, C. (2000a) 'Sports, Fascism and the Market', in T. Tannsjo \& C. Tamburrini (eds) $V$ alues in Sport, London: E \& FN Spon.

Tamburrini, C. (2000b) 'What's Wrong with Doping?', in T. Tannsjo \& C. Tamburrini (eds) Values in Sport, London: E \& FN Spon.

Taylor, I. (1971) 'Soccer Consciousness and Soccer Hooliganism', in S. Cohen (ed.) Images of Deviance, Harmondsworth: Penguin.

Taylor, I. (1991) 'English Football in the 1990s: taking Hillsborough seriously', in J. Williams \& S. Wagg (eds) British Football and Social Change, London: Leicester University Press.

Walsh, A.J. (1998a) 'Market Pathology and the Range of Commodity Exchange: a preliminary sketch', Public Affairs Quarterly, 12(2): 203-219.

Walsh, A.J. (1998b) 'Teaching, Preaching, and Queaching about Commodities', Southern Journal of Philosophy, 36: 433-452.

Walzer, M. (1983) Spheres of Justice, Oxford: Blackwell.

\section{Notes}

i Sports such as association football and rugby were codified by the English public schools in the latter half of the nineteenth century. The new codes provided a rationalized, more civilized, universal framework for competing teams, in contrast to the informal, local, 'folk' variants of football that had been played since before the Middle Ages (Elias \& Dunning 1986; Guttmann 1978; Holt 1989: 36-41, 84-6).

ii Gruneau (1983: 63), for example, notes that Canadian sport has passed through four historical phases. First, the preliminary phase saw games incorporated into school programmes, while leisure associations developed. Second, a consolidation phase saw bourgeois class practices becoming more central to sport's technical and moral components. Third, a phase of commodification and cartelization involved commercial forms of game activity becoming more fully integrated within the market system. Fourth, a phase of expanding State influence within sport in concert with established sporting institutions. Although phase three is the most obviously related to sport's commodification, different kinds of commodification of sporting practices and materials are prevalent in all phases.

iii In the early 1980s, a controlling interest in Manchester United was worth only £10 million (Giulianotti 1999: 99).

iv In 1979, the British transfer record for a player was $£ 1,180,000$; in 1996 the record became $£ 15$ million. In the early 1990s, the top earning UK player was paid around £5,000 per week; in 2000, the top-earning UK player was paid £50,000 each week. In 1978, 92 English league clubs earned £9.8 million from a four-year television deal; in 2000, 20 English clubs invited collective bids of up to $£ 2$ billion for a three-year package of televised football.

v In 1990, a season ticket for Manchester United could be bought for £76; by 1999, a season ticket in one of the cheapest ground sections cost $£ 380$ (Brown \& Walsh 1999: 44-5). 
vi In South America, the professional leagues are now actively considering the abandonment of the 'socio' system, in order to compete with the rich European clubs which continue to lure the best South American players. In France, the Marseille club has an unusually intimate relationship with its supporters, reflected in relatively cheap seating inside the stadium and inexpensive club merchandise. Indicatively, the club has struggled badly in recent years in its quest to compete with other, strongly supported teams from France and in Europe generally.

vii On this point, see Taylor (1971).

viii Goldman and Papson (1999) and Andrews (1997), for example, have provided critical social and semiotic analyses of Nike culture, noting the way in which the 'sign of the swoosh' has become fetishized, to remove its real sporting components. While they may mimic the marketing semiotics of companies such as Nike, this process is particularly problematic for sports clubs, given their historical ties to specific places.

ix For example, AS Roma have contracted with FC Nice, and Juventus have an agreement with Sheffield United. Manchester United have a particularly close link with the Belgian club Royal Antwerp which will allow them to 'launder' non-European players more quickly than is possible in England, thus easing any possible employment problems.

$\mathrm{x}$ For example, in France, the leading club PSG is owned by Canal Plus; in England, Caspian bought into Leeds United while numerous other companies (such as BSkyB and ON-digital) have small share-holdings in other top clubs; in Spain, Antenne3 bought into Real Madrid; in Germany, Bertelsman took a considerable share in Hertha Berlin.

xi On this issue, see Greenfield \& Osborn (1999). One commentator has compared pre-1960s football contracts to those obligating military service (Hargreaves 1986).

xii See Mason (1996) on English football heroes and Horak and Maderthaner (1996) on Austrian heroes.

xiii These commodities would include beer, whisky, tomato ketchup, radios, hi-fis, bedspreads and leisure wear.

Banks, credit card companies, building societies and holiday firms have joined with clubs to offer special consumer packages for supporters.

xiv On this point, see Hoch (1973) and Loland (2000: 53).

${ }^{x v}$ D'Agostino (1981:17) concludes, "The ethos of a game is that set of unofficial, implicit conventions which determine how the rules of that game are to be applied in concrete circumstances." In our view, the thrust of D’Agostino's (1981) paper is correct, in legitimizing the 'ethos' of the game, but his definition is unduly dependent upon the interpretation of rules. In seeking to clarify the ethos of games and sports, we suggest that it is at least as useful to examine the popular cultures surrounding the various participants within that sport - players, fans, match officials, club and association authorities and so on.

xvi See Bourdieu (1984) for an analysis of how specific cultural practices (including sporting ones) are employed by the wealthier and more educated classes to distinguish themselves from the lower social orders.

xvii In football, the amateurist argument was employed world-wide to exclude or to reduce the participation of working-class or non-white players and administrators, thereby cementing the hegemony of the upper classes or (in South America or Africa) the white colonial elite (Giulianotti 1999). In the UK, the sporting distinction centred on the 'gentlemen' amateurs (who claimed to uphold the 'spirit of the game') and professional 'players' (who were viewed as too keen on gamesmanship) (Hargreaves 1986: 67-8; Holt 1989: 104-5). In England, the dispute over professionalism prior to World War 1 led to serious divisions between the 'old money', amateurist upper middle-classes and aristocrats in the South, and the 'new money', pro-professional entrepreneurs in the North (Mason 1980).

xviii Kidd (1984: 72-3) notes that, at the ancient Olympic Games, spectators tended to be charged exorbitant prices while champion athletes, who trained effectively as professionals, were rewarded with lavish prizes. Kidd (1984: 80) also rejects the amateurist mythologies propounded in the late $19^{\text {th }}$ century and beyond, that the ancient Olympics entered some kind of decline when professionalism of athletes became more apparent.

xix De Coubertin was a decided anglophile who had been greatly inspired by the 'Games Revolution' in English public schools, initiated by Thomas Arnold with the aim of controlling boys and shaping them into 'muscular Christians' (Hargreaves 1986: 66). Consequently, De Coubertin followed strongly the amateurist myth surrounding the ancient Olympics and contemporary sport, while celebrating the subjugation of the intellect to bodily exercise. He staunchly opposed the athletic participation of women and professionals, and the morally corrupting nature of modern, industrial life (Holt 1989: 129). His pursuit of physical fitness among young men also carried social hygienist and nationalist dimensions, with particular relevance to the build-up of international tensions prior to World War 1 (cf. Hoberman 1984: 129). Hence, while De Coubertin's sporting ethos initially appeals, he does crystallize a number of historical and ideological problems in the amateurist position.

${ }^{x x}$ In the UK, for example, the amateurist principle served to exclude working-class players during the late $19^{\text {th }}$ 
century. In Brazil, amateurism was an important device that enabled the rich white elites to exclude working-class mulattos and blacks from participating until at least the 1920s.

xxi Most football clubs began as private member associations, and so were geared towards providing facilities or an organisational framework for local recreation. In Scotland, the Glasgow Celtic club was founded as a charitable institution for the local, Irish-Catholic poor.

xxii Fanzines are magazines that are traditionally produced by fans and sold to fellow supporters often in informal circumstances, such as at street-corners outside football grounds. Most fanzines are tied to individual clubs.

xxiii Social theorists who take the 'linguistic turn' in the human sciences seriously include Dilthey, Gadamer, Habermas and Giddens.

xxiv "Fans are far more aware of their rights and that's because clubs see them as consumers ... In the language of the consumer the logic is that fans will expect more, more in the way of success and more in terms of standards on the pitch.” John Williams, quoted in The Guardian, 4 December 1999.

xxv See, for example, Coddington (1997: 74-5) and Taylor (1991: 14-15).

xxvi Habermas argued that political issues within capitalist societies have tended to be supplanted by a technical management of the economy. When economic problems or crises occur, the system inevitably undergoes a legitimation crisis.

xxvii The term 'spruce up' is rather too vague and open-ended here; it might, in some instances, constitute a key problem for some practice-communities, as ‘sprucing up’ and commodification are presented as symbiotic social forces. For example, the 'modernization' of elite level football in the UK since 1990 could be said to have 'spruced up' stadia and the quality of players, although as we have argued here, the power balances within the game's practice-communities have shifted inexorably towards those with money.

xxviii On this, we share Loland's (2000: 54) view that 'the guiding norms of the devoted fan' enable him or her to enjoy the sport in a manner similar to that of the participant.

xxix The UK government has introduced a system of 'share-pooling' whereby very small shareholders within clubs may collectivise into a more effective force (The Guardian, 2 October 1999). This encourages fans to have potentially more impact although it does still operate within the logic of the market.

${ }_{\mathrm{xxx}}$ On this, see Walsh (1998a)

xxxi The list of matches which should be protected from the market may be ironed out in due course. It should not include all football fixtures, as this would be impractical for television's purposes, and would also have a very adverse effect on match attendance figures, thereby corrupting the overall nature of football-watching experience. Arguably, the list should include all club and international fixtures that are played abroad; and all club fixtures that are defined as prestigious by the fact that they are declared to be 'full houses' on the eve of the match.

xxxii Professional clubs currently offer some concessionary prices for family groups and the retired into some parts of the ground (usually those with poor sight-lines). This policy might be expanded to include the unwaged (students, unemployed, domestic workers) and reapplied to most ground sections.

xxxiii In the UK, the Office of Fair Trading (OFT) won a landmark civil action against the manufacturers of replica football shirts on the grounds of illegal pricing. The OFT lost a separate case in which it had claimed that the Premier League of clubs was acting illegally, as a cartel, in the sale of collective television rights for all matches. Perhaps the most effective strategy of this kind to date has been the International Labour Organisation's use of international law to highlight the employment of child labourers in Pakistan in the manufacture of footballs for sale to First World nations. 